\title{
Pharmaceutical Solid Form Formation via Vapour-Assisted Tumbling (VAT) - A Solvent Efficient Process with Potential Industrial Applications
}

\author{
Alexander J. Stirk, ${ }^{* a}$ Fabio E. S. Souza, ${ }^{a}$ Jenny Gerster, ${ }^{a}$ Fatemeh M. Mir, ${ }^{a}$ Avedis Karadeolian, ${ }^{a}$ and Allan W. Rey ${ }^{a}$
}

a.Apotex Pharmachem Inc., 34 Spalding Drive, Brantford, Ontario, Canada, N3T 6B8, *astirk@apotexpharmachem.com.

\begin{abstract}
Crystallisations on both the academic and industrial scale often use large volumes of solvent. In order decrease the environmental impact of such processes, new techniques must be discovered that increase the efficiency of the solvents used. Introduced here is a process that combines repurposed industry standard hardware and aspects of mechanochemistry to produce a technique we call "Vapour Assisted Tumbling" (VAT). Pharmaceutical and well-known cocrystals and salts were formed by tumbling the coformers in an atmosphere of vaporised solvent, in this study, methanol (MeOH). This was done inside a custom built analogue of an industrial rotary cone dryer (RCD). It was found that a desired solid form could be obtained as monitored by powder X-ray diffraction and differential scanning calorimetry. By repurposing industrial RCDs, it is feasible that solid forms can be crystallised with both minimal and reusable/recyclable solvent - drastically lowering the environmental impact of such transformations.
\end{abstract}

\section{Introduction}

Manufacturing pharmaceutical solid forms, especially on an industrial scale, requires both efficiency and a high-purity product. To achieve this, there have been many crystallisation methods tailored for pharmaceutical solid forms. Current methods for generation of solid forms include evaporation, slurry conversion, melt extrusion, mechanochemical grinding, spray-drying, spray-congealing, solvent-antisolvent, supercritical $\mathrm{CO}_{2}$, freeze-drying, jet dispensing, high shear wet granulation, sublimation and acoustic methods. ${ }^{1-7}$ Even with the numerous existing approaches to solid form generation, a significant challenge remains to produce industrial quantities of pharmaceutical solids, predominantly cocrystals, reliably and economically while adhering to all regulatory guidelines within good manufacturing practices (GMP).8,9 Currently, solventbased methods are still preferred by major pharmaceutical industry, despite the fact that reliance on solvent methods increases costs and the environmental impact. ${ }^{10}$ Such solvent methods can also create high levels of residual solvent, requiring further time-consuming processing. If we are to create a sustainable chemical industry, further innovations are required in the large-scale manufacture of solid form pharmaceuticals.

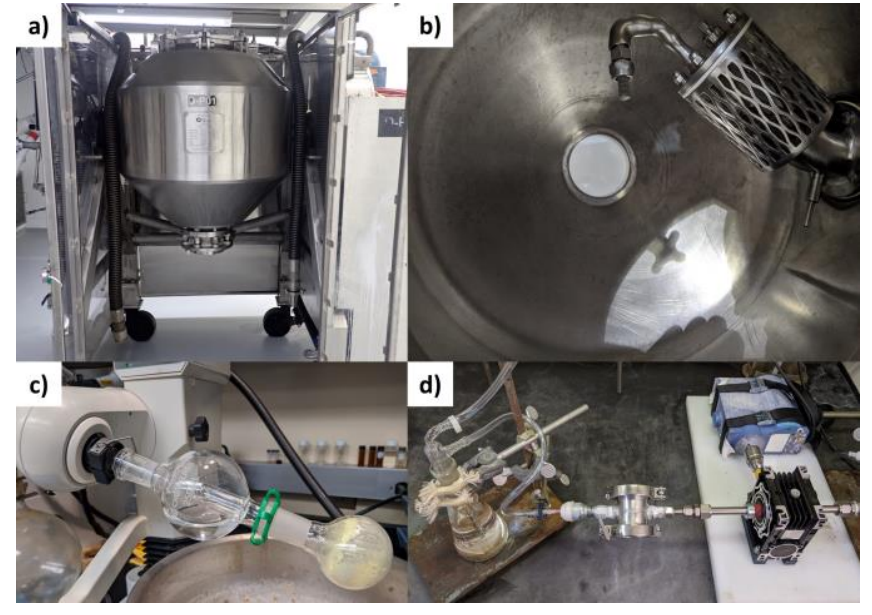

Fig. 1 a) The outside of a Hastelloy 250 L RCD with a 163 L working capacity. b) A view of the inside of a $51 \mathrm{~L} R C D$ with a $28 \mathrm{~L}$ working capacity. The "arm" can control the inside environment of the RCD. Not pictured - the "sock" filter that would usually surround the mesh of the arm. c) The VAT Mk.1 apparatus. A simple rotary evaporator solvent trap acts as a reservoir. The solids are added to the round bottomed flask and slowly rotated. d) The VAT Mk.10b. To the right of the picture, a flow of $\mathrm{N}_{2}$ carrier gas is bubbled though a solvent reservoir that passes through the sample tumbler. To the left of the picture, an overhead stirrer is geared down using a worm gear to provide a steady rate of rotation to the stainless-steel tumbler. 


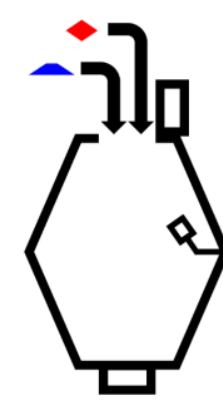

1) Load powdered
reactants into rotary
cone dryer

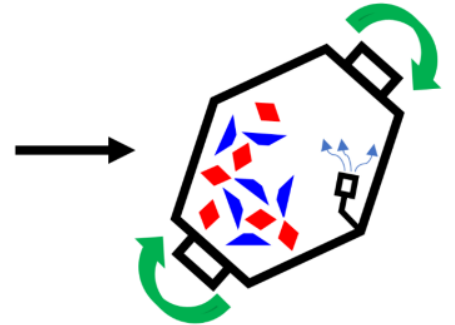

2) Tumble in solvent vapour

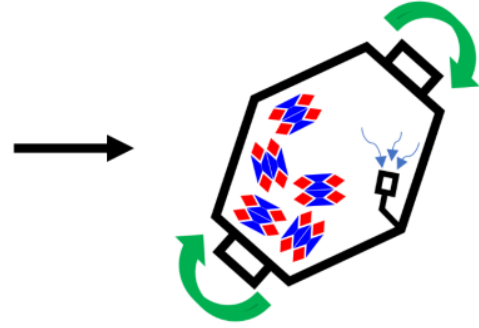

3) Tumble under vacuum to dry. Solvents collected and stored

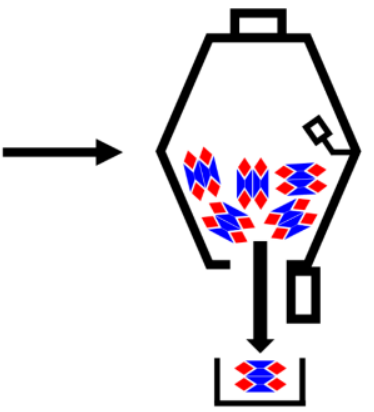

4) Empty the rotary cone dryer

Fig 2. A simplified cartoon of the VAT process involving 4 main steps. Loading the conformer reactants, tumbling in solvent vapour, drying under vacuum, and unloading the cocrystal.

One potential avenue for development in this regard is utilising solid-solid or solid-gas reactivity. Such a phenomenon is already well-known in the pharmaceutical field as evidenced by the requirement to test and control against the interconversion of solid forms, such as hydration of an anhydrous form, that can occur upon exposure to atmospheric humidity. ${ }^{10-16}$ If one could harness this vapour-assisted solid-solid conversion with other solvents, then the use of solvents could be considerably lowered. Further to this, if the material can be crystallised and dried within the same process, time and energy input are also majorly reduced.

Solid-solid transformations have been reported to be dependent on the generation of a deliquescent phase during the phase change. A "catalytic effect" of different solvent vapours upon powders was also found to create new solid forms. ${ }^{11,12}$ This solvent-vapour interaction is also exploited in "vapour-digestion" and "accelerated aging" processes. ${ }^{13-20}$ Further to this, the choice of solvent vapour has also been shown to have an effect on the nature of the solid form produced. ${ }^{21}$ These vapour-assisted transformations have been already discussed as a possible green alternative to solution crystallisation. ${ }^{22-24}$ Nevertheless, despite the multiple precedents in the scientific literature, solid-solid and solid-gas transformations are
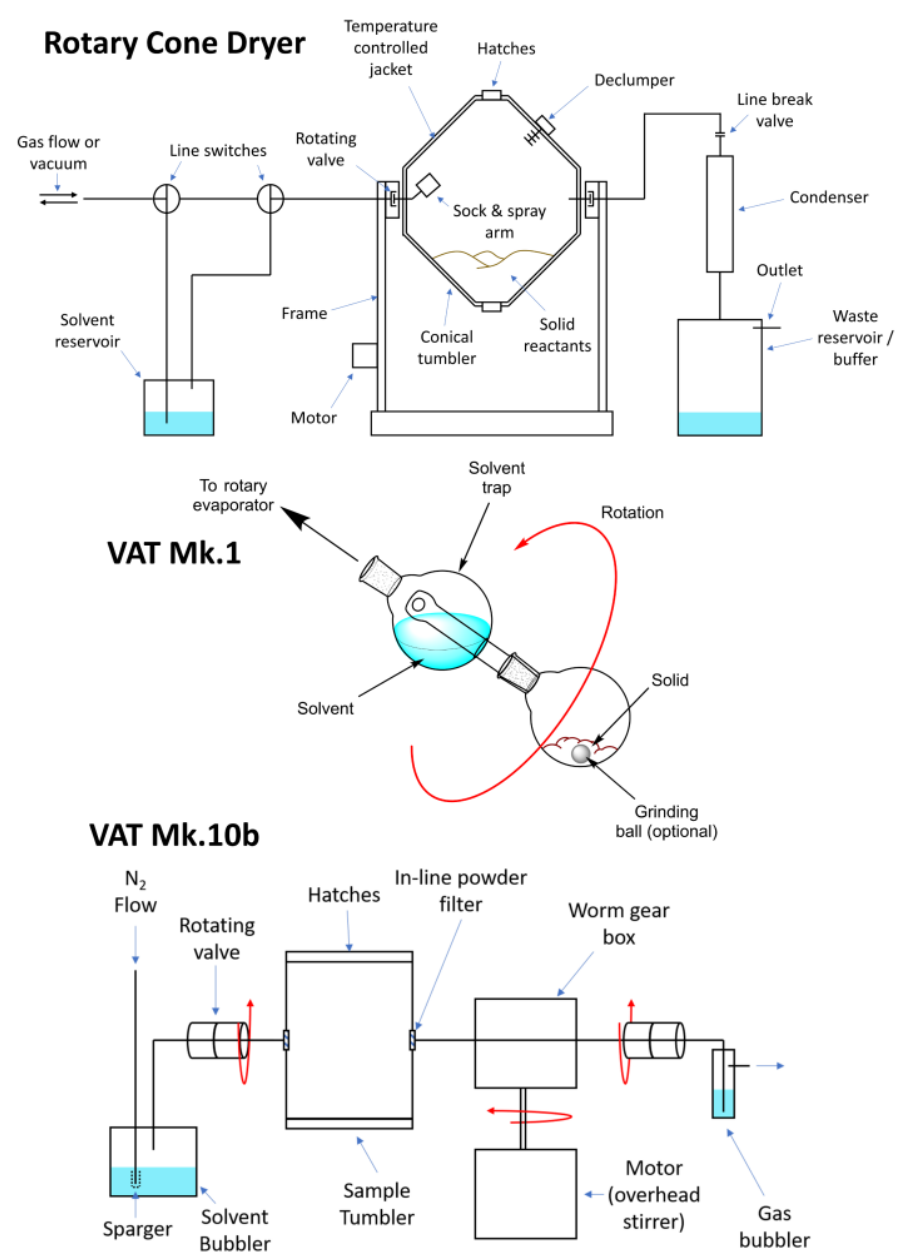

Fig. 3 Simplified schematics of the devices. Top) A rotary cone dryer. Middle) The VAT Mk.1 using a repurposed rotary evaporator. Bottom) The VAT Mk.10b apparatus that emulates the basic functions of a rotary cone dryer. 
currently under-utilized in industry, as the development of processes using such transformations is usually hindered by scalability issues and concerns.

This report presents a new approach, termed Vapour-Assisted Tumbling (VAT), a simplified process as shown in Fig. 2. VAT is an attempt to create a reliable method of producing such vapour-induced transformations for future use in the pharmaceutical industry. It would potentially make use of the common industrial rotary cone dryer to bring solid components into close contact in an environment of vapourised solvents with constant agitation, i.e. "tumbling". In this report both cocrystals and salts were formed in the solid state using minimal solvent volumes.

Rotary cone dryers (RCDs), also known as rotary tumble dryers, rotary double cone dryers or "rotocones" (shown in Fig 1, schematic shown in Fig 3) are in widespread use throughout industrial chemistry and are commonly used to dry solids, for instance pharmaceutical solids. These dryers are capable of efficiently drying solid compounds through controllable heating and constant agitation i.e. tumbling. ${ }^{25}$ It is this constant agitation that provides good surface-tosurface interaction between particles that can allow for solid-state phase transformations and cocrystallisations, and the tumbling speed can be controlled to provide different levels of agitation. Additional motorised "choppers" can be attached to the inside of the cone to break up large clumps, ensure flowability of the powders and prevent "balling" during the drying process. Since the tumbling chamber is sealed and commonly lined either with steel, glass or other inert materials, a wide range of reactants and solvents may be used safely.

Many RCDs are also "jacketed" allowing for fine control of the internal temperature of the dryer. Additionally, some models of industrial rotary cone dryers can spray a fine mist of vapourised solvent upon the solids. This "misting" mode may be considered akin to the common process of liquid-assisted grinding (LAG) in mechanochemistry in which very low catalytic amounts of solvent are used.

RCDs can also be made gas tight and pressurised allowing for a wide variety of gaseous environments, even highly corrosive ones. One such example is the commercial preparation of amorphous ziprasidone hydrochloride. Ziprasidone freebase can be safely tumbled under an $\mathrm{HCl}_{(\mathrm{g})}$ atmosphere inside an $\mathrm{RCD}$, causing a solid-gas phase proton transfer creating the hydrochloride salt in commercial quantitative yields and meeting all purity specications. ${ }^{26,27}$ Typically these transformations were done on $200 \mathrm{Kg}$ scale in $1500 \mathrm{~L} \mathrm{RCD}$. With capacity volumes commonly ranging between $5-10,000$

L, RCDs are already scaled to the demands of pharmaceutical and chemical industries; thus when transitioning to larger scales, VAT potentially would offer an industrially applicable process involving accelerated aging in combination with low-energy agitation.

To assess the scope of the VAT technique, smaller analogues that mimic the basic functions of a common industrial rotary cone dryer (RCD) were built, schematics of which can be seen in Fig. 3 (further designs are detailed in the SI). These analogues were built with a focus on the tumbling motion and the controlled environment of solvent vapour that can be maintained in an RCD. For an accessible laboratory experiment, VAT can be conducted using a repurposed rotary evaporator (VAT Mk.1, Fig 3.). The solid forms targeted included cocrystals and salts with scales ranging from 100 mg to $15 \mathrm{~g}$ of total materials.

\section{Experimental}

Chemicals used in this work were either purchased from commercial sources or obtained from company resources and in-house synthetic processes. PXRD data of all samples were acquired using a Bruker AXS D8 Discover (Bruker-AXS, 

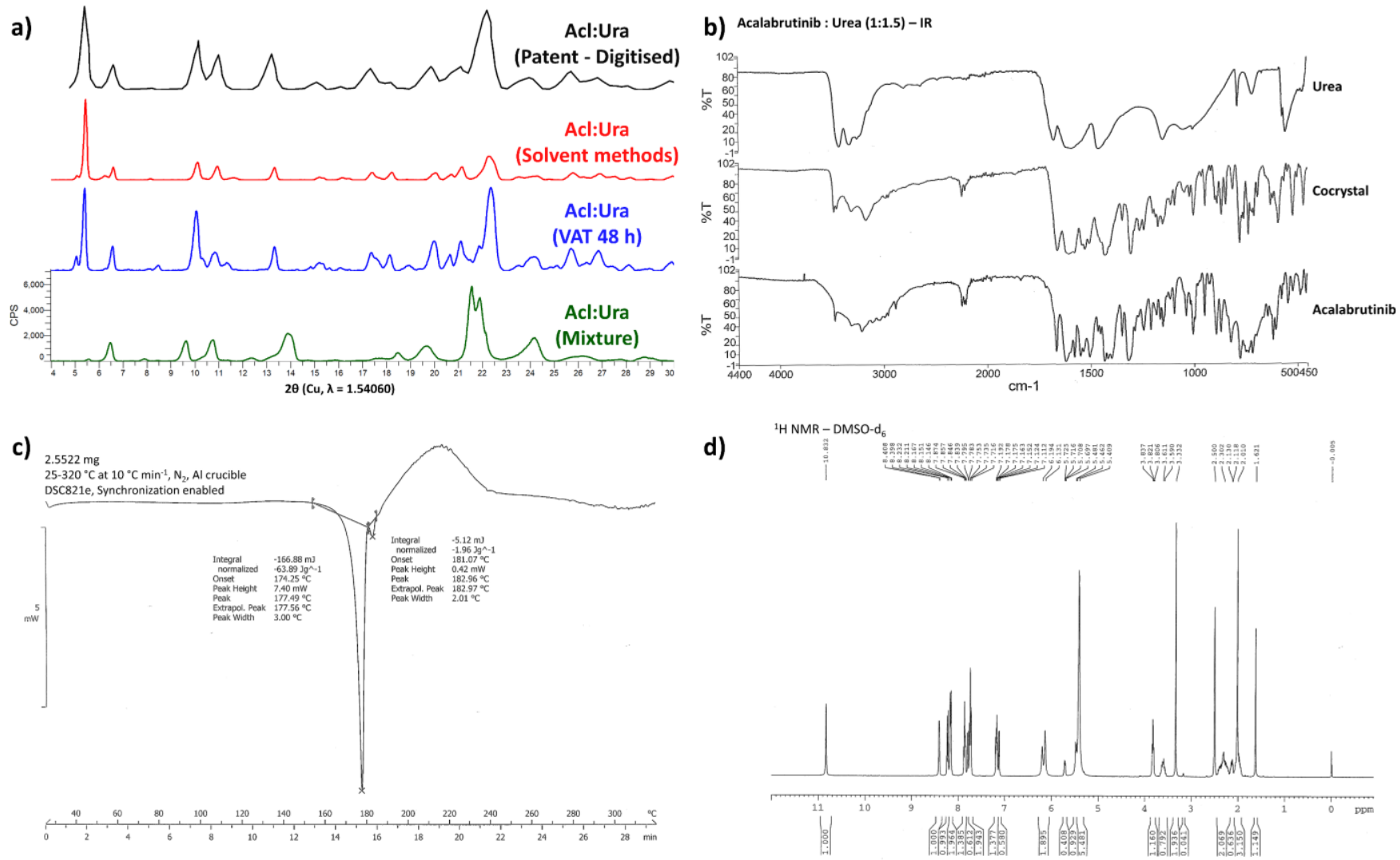

Fig 5. Characterisation of the Acl:Ura (1:1.5) cocrystal. a) PXRD comparisons of the Acl:Ura cocrystal. upon dry mixing for $1 \mathrm{hr}$, after the VAT process. The single crystal structure of the Ari:Ura cocrystal has not been previously published, so a comparison with its reported solvent crystallisation and digitised patent PXRD is shown instead. b) FT-IR spectral comparison between the components and the cocrystal. c) DSC thermogram of the cocrystal. d) A ${ }^{1} \mathrm{H}$ NMR (DMSO- $d_{6}$ ) of the final material from the VAT process.

Karlsruhe, Germany) equipped with a PILATUS3 R 100K-A $83.8 \times 33.5 \mathrm{~mm}^{2}$ area detector and an Incoatec Microfocus Source $(I \mu S) \mathrm{Cu}$-anode $(\lambda=1.54060 \AA$ ) X-ray source. X-rays were generated at $50 \mathrm{kV}$ and $1000 \mu \mathrm{A}$ and focused with a micro mask $0.1 \mathrm{~mm}$ plug-in pinhole microslit. Each sample was placed on a zero background Si holder and mounted on the UMC 150 sample stage. Each sample was oscillated on the $x$ and $y$ axis with a $1 \times 1 \mathrm{~mm}$ amplitude. Either one frame of data was collected using either still scans or multiple frames taken and then merged. Raw diffraction frames were merged and integrated using Bruker DIFFRAC.EVA V5.2 (Bruker-AXS, Karlsruhe, Germany). Differential Scanning Calorimetry (DSC) was performed with a Mettler-Toledo DSC821e or a TA Q2000. Samples were loaded into Al $40 \mu \mathrm{L}$ crucibles and sealed with perforated Al lids. Experiments were conducted between $25-320{ }^{\circ} \mathrm{C}$ at $10{ }^{\circ} \mathrm{C}$ min ${ }^{-1}$ with synchronisation enabled. The data was processed using the STARe 9.3 software. IR spectroscopy was performed using a PerkinElmer Spectrum Two FT-IR using the UATR accessory. NMRs were taken using a Bruker $400 \mathrm{MHz}$.

As much as possible the examples were compared to previously reported structures obtained from the CCDC and using Mercury to predict the associated PXRD patterns. ${ }^{28}$ For data only available in patent literature, the PXRD was overlaid with the experimentally obtained pattern using WebPlotDigitizer due to the lack of published data and other characterisation methods. ${ }^{29} \ddagger$

\section{Rotary Cone Dryer - Analogues}

Over the course of the process development, several different approaches to VAT were made. The two major "modes" of the VAT used were either "back-fill" or "flow-through" modes. The 
back-fill mode involved placing the solids under vacuum, closing the system, and then back-filling with the solvent vapour from a reservoir. The flowthrough mode involved bubbling an inert carrier gas (such as $\mathrm{N}_{2}$ ) through the solvent and passing the gas over the tumbling solids. To enhance the carrier gas efficiency, a sparger was used to increase the gasliquid interface by reducing the bubble size and thus help to saturate the gas with solvent vapour. To simulate the misting mode of the RCD, some experiments were conducted with a small volume of solvent added directly to the solids - similar to a LAG process.

Each version of the VAT apparatus was given a "Mark" (Mk) designation. In terms of simplicity, the Mk.1 makes use of the ubiquitous laboratory rotary

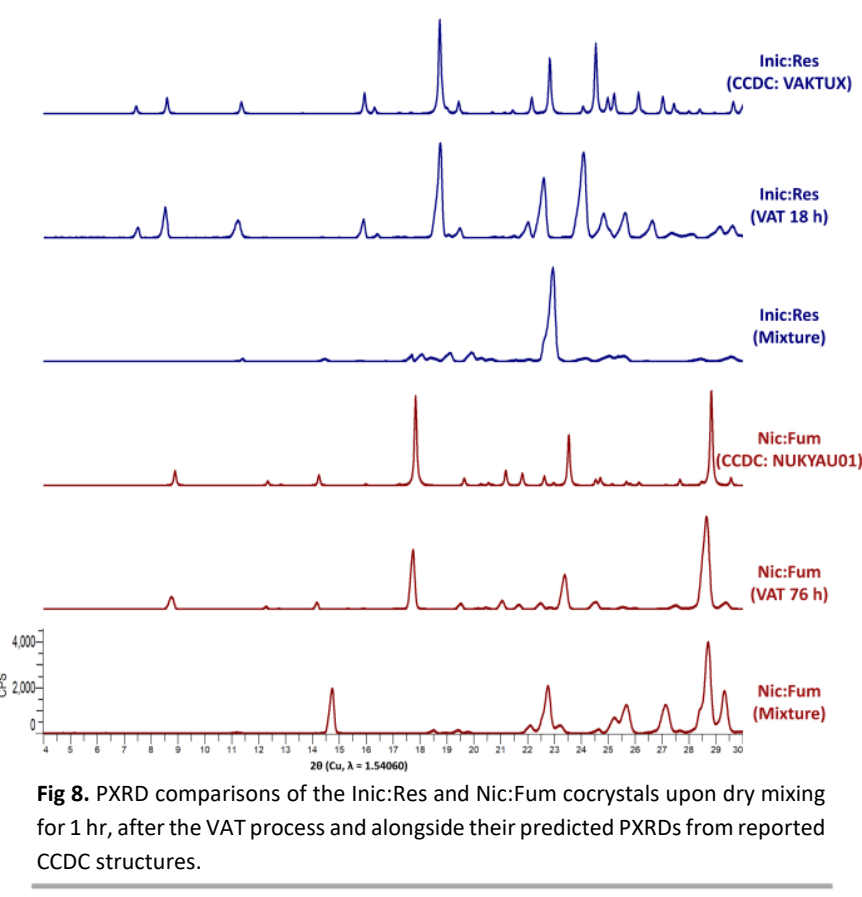
evaporator and solvent trap and can be replicated in most laboratories. The most successful design and closest in function to an RCD was the custom made "Mk.10b" (Fig. 1d \& 3). The Mk.10b was custom designed to mimic the basic features of a standard RCD, that being; a stainless-steel construction, a cylindrical or conical sample tumbler, and the ability to do both back-fill and flow-through batch modes. Schematics and other VAT apparatus designs can be found in the supporting information. Fine temperature control on the Mk.10b was met with some difficulty, so was eventually deemed outside of the scope of study. On a full-sized RCD however, fine temperature control is usually standard.

For VAT in the Mk.10b each of the sample powders in their stated stoichiometries were tumbled in the sample

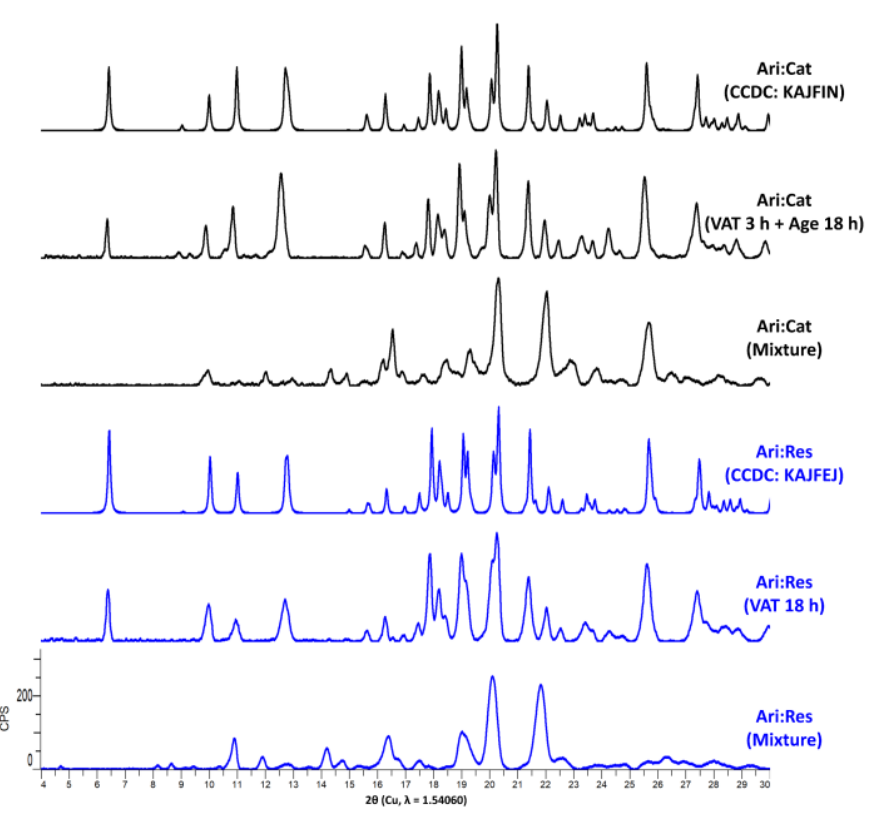

Fig 6. PXRD comparisons of the Ari:Cat and Ari:Res cocrystals upon dry mixing for 1 $\mathrm{hr}$, after the VAT process and alongside their predicted PXRDs from reported CCDC structures. tumbler at a constant $9 \mathrm{rpm}$, consistent with RCD standard operating procedures that range between 3-9 rpm depending on the mass and bulk density of the load.These experiments were done at ambient temperature with a flow of $\mathrm{N}_{2(\mathrm{~g})}$ bubbled through the solvent reservoir. This $\mathrm{N}_{2} / \mathrm{MeOH}$ flow was passed through the sample tumbler containing the mixed powders. The powders were periodically evaluated by PXRD for cocrystal/salt formation.

\section{Cocrystals}

\section{Acalabrutinib : Urea (1:1.5) Cocrystal}

Acl $(5.00 \mathrm{~g}, 10.74 \mathrm{mmol})$ was milled by hand in a mortar and pestle for $2 \mathrm{~min}$ and added to the sample tumbler of the VAT Mk.10b. Ball-milled urea $(0.97 \mathrm{~g}$, $16.11 \mathrm{mmol}$ ) was also added to the sample tumbler. 
The solids were tumbled for $1 \mathrm{~h}$ in atmospheric conditions. A flow of $\mathrm{N}_{2}$ through $\mathrm{MeOH}$ was introduced into the sample tumbler $\left(\sim 420 \mathrm{~mL} \mathrm{~min}{ }^{-1}\right)$. After $24 \mathrm{~h}$ of tumbling in $\mathrm{N}_{2} / \mathrm{MeOH}$ the solids were removed from the sample tumbler. Recovered mass: $5.42 \mathrm{~g}$. A DSC showed an endothermic peak at $174.25^{\circ} \mathrm{C}$ followed by another small endotherm at $181.07^{\circ} \mathrm{C}$.

\section{Aripiprazole : Catechol (1:1) Cocrystal}

Milled aripiprazole $(5.00 \mathrm{~g}, 11.15 \mathrm{mmol})$ and Cat $(1.23 \mathrm{~g}, 11.15 \mathrm{mmol})$ were added to the sample tumbler of the VAT Mk.10b and tumbled for $1 \mathrm{~h}$ in atmospheric conditions. The tumbling was resumed with a flow of $\mathrm{N}_{2}$ bubbled through the $\mathrm{MeOH}$ reservoir ( $77 \mathrm{~mL} \mathrm{~min}^{-1}$ ). After $1 \mathrm{~h}$ of tumbling in $\mathrm{N}_{2} / \mathrm{MeOH}$ the solid had become very sticky and had balled clumps. The balls of sticky solid were broken up as much as possible before tumbling in $\mathrm{N}_{2} / \mathrm{MeOH}$ resumed. After a further hour ( $2 \mathrm{~h}$ in total), the solid was observed to be no longer sticky, with many small balls. The solid was gently broken up in a mortar and pestle before returning to the sample tumbler. The solid was then left enclosed inside the sample tumbler without tumbling, but with a low flow of $\mathrm{N}_{2} / \mathrm{MeOH}\left(\sim 45 \mathrm{~mL} \mathrm{~min}^{-1}\right.$ ) overnight ( $18 \mathrm{~h}$ ). The solids were then removed from the sample tumbler. Recovered mass: $5.79 \mathrm{~g}$. A DSC showed a small endotherm at $94.01{ }^{\circ} \mathrm{C}$ followed by the main endothermic melting peak onset at $119.18{ }^{\circ} \mathrm{C}$ (Reported Ari:Cat M.P. $=121.2{ }^{\circ} \mathrm{C}$ ) without any noticeable peak from Ari (reported M.P. $=139.0^{\circ} \mathrm{C}$ ).

\section{Aripiprazole : Resorcinol (1:1) Cocrystal}

Milled aripiprazole $(3.00 \mathrm{~g}, 6.96 \mathrm{mmol})$ and resorcinol $(0.74 \mathrm{~g}, 6.69 \mathrm{mmol})$ were added to the sample tumbler of the VAT Mk.10b and tumbled under ambient conditions. After $1 \mathrm{~h}$, a flow of $\mathrm{N}_{2} / \mathrm{MeOH}\left(\sim 77 \mathrm{~mL} \mathrm{~min}^{-1}\right)$ was introduced to the tumbler. After a further $1 \mathrm{~h}$, the sample had balled clumps. The balls of powder were crushed with a spatula and the sample tumbled for a further $3 \mathrm{~h}$. After a total of $4 \mathrm{~h}$ being tumbled in $\mathrm{N}_{2} / \mathrm{MeOH}$, the experiment was stopped, and the solids removed. Recovered mass: $3.70 \mathrm{~g}$. A DSC of the final material showed three small endotherms at $107.82^{\circ} \mathrm{C}, 134.81$

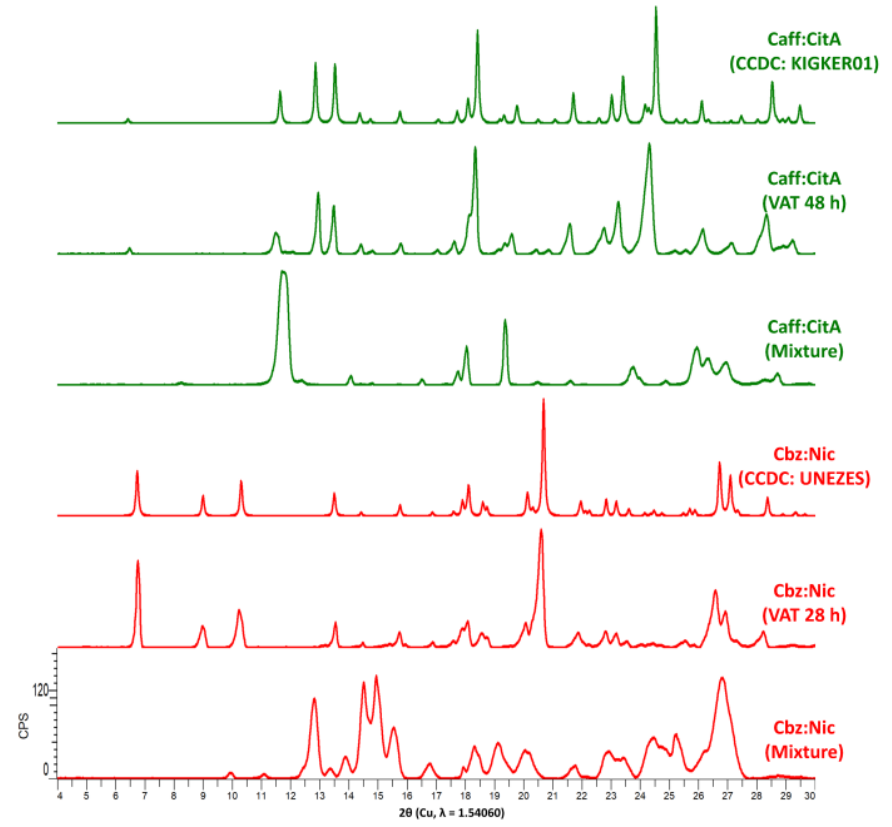

Fig 7. PXRD comparisons of the Caff:CitA and Cbz:Nic cocrystals upon dry mixing for $1 \mathrm{hr}$, after the VAT process and alongside their predicted PXRDs from reported CCDC structures.
${ }^{\circ} \mathrm{C}$ and $138.62{ }^{\circ} \mathrm{C}$. The major endotherm was seen at $175.37^{\circ} \mathrm{C}$.

\section{Caffeine : Citric Acid (1:1) Cocrystal}

Milled caffeine $(5.00 \mathrm{~g}, 25.75 \mathrm{mmol})$ and citric acid $(4.95,25.75 \mathrm{mmol})$ were added to the sample tumbler of the VAT Mk.10b and tumbled dry for $1 \mathrm{~h}$. After $1 \mathrm{~h}$, a flow of $\mathrm{N}_{2} / \mathrm{MeOH}\left(\sim 77 \mathrm{~mL} \mathrm{~min}^{-1}\right)$ was introduced to the tumbler. After a total of $34 \mathrm{~h}$ tumbling in $\mathrm{MeOH}$ the experiment was stopped and the solids removed. Recovered mass: $9.29 \mathrm{~g}$. A DSC of the final material showed two sharp endotherms at $153.74{ }^{\circ} \mathrm{C}$ and $163.67^{\circ} \mathrm{C}$.

\section{Carbamazepine : Nicotinamide (1:1) Cocrystal}

Milled carbamazepine $(5.00 \mathrm{~g}, 21.16 \mathrm{mmol})$ and nicotinamide $(2.58,21.16 \mathrm{mmol})$ were added to the 


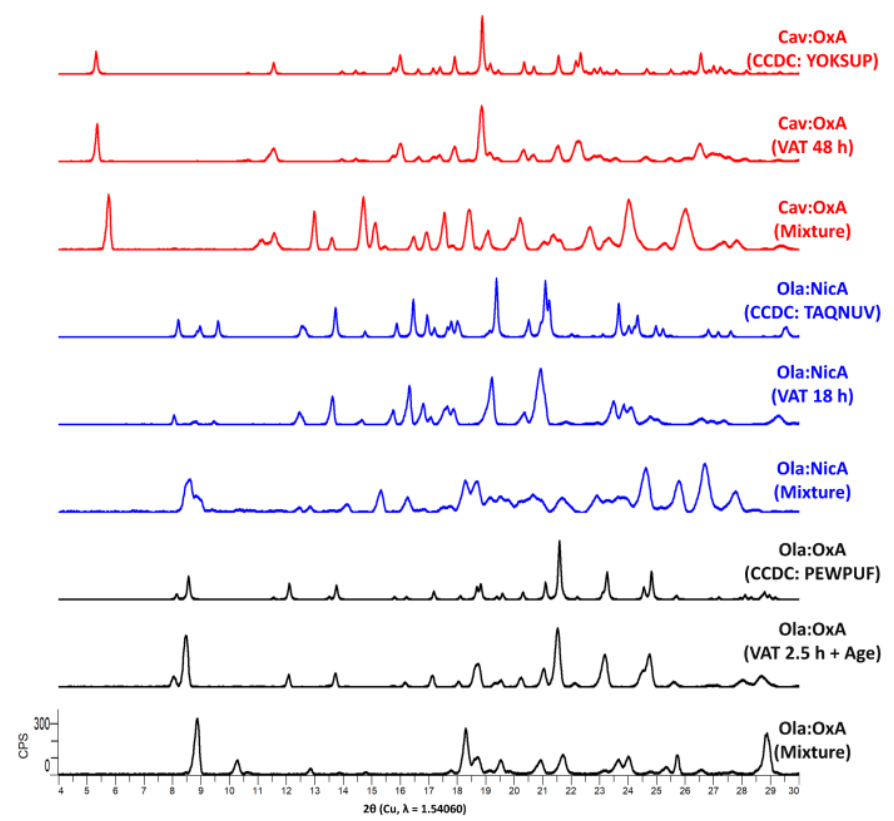

Fig 9. PXRD comparisons of the salts. The mixed powders containing each component were tumbled in the VAT apparatus under ambient conditions for $1 \mathrm{~h}$. The PXRD of the final obtained material after the VAT process is shown. Detailed comparisons with time sampled PXRDs including DSC analysis can be found in the ESI. Intensities are normalised for clarity. sample tumbler of the VAT Mk.10b and tumbled dry. After $1 \mathrm{~h}$, a flow of $\mathrm{N}_{2} / \mathrm{MeOH}(\sim 77 \mathrm{~mL} \mathrm{~min}-1)$ was introduced to the tumbler. After a further $20 \mathrm{~h}$ of tumbling in $\mathrm{N}_{2} / \mathrm{MeOH}$ vapour an additional portion of Nic $(0.26 \mathrm{~g}, 2.12 \mathrm{mmol})$ was added. After a further $4 \mathrm{~h}$ of tumbling, no more peaks of either $\mathrm{Cbz}$ or Nic could be seen in the PXRD. Recovered mass: $7.28 \mathrm{~g}$. A DSC of the final material showed two very small peaks at $123.72{ }^{\circ} \mathrm{C}$ and $126.68{ }^{\circ} \mathrm{C}$, with the major sharp endotherm being seen at $158.70^{\circ} \mathrm{C}$.

\section{Isonicotinamide : Resorcinol (1:1) Cocrystal}

Milled resorcinol $(2.50 \mathrm{~g}, 22.71 \mathrm{mmol})$ and isonicotinic acid ( $5.55 \mathrm{~g}, 45.41 \mathrm{mmol}$ ) were added to the sample tumbler of the VAT Mk.10a and tumbled dry. After $1 \mathrm{~h}$, a flow of $\mathrm{N}_{2} / \mathrm{MeOH}\left(\sim 420 \mathrm{~mL} \mathrm{~min}^{-1}\right)$ was introduced to the tumbler. After a further tumbling for $18 \mathrm{~h}$ no peaks from either the Res or Inic

remained. Recovered mass: $7.70 \mathrm{~g}$. A DSC showed two very small endotherms at $69.13^{\circ} \mathrm{C}$ and $141.49{ }^{\circ} \mathrm{C}$, with the major sharp endotherm being seen at $152.24^{\circ} \mathrm{C}$.

\section{Nicotinamide : Fumaric Acid (1:1) Cocrystals}

Milled nicotinamide $(5.00 \mathrm{~g}, 40.94 \mathrm{mmol})$ and fumaric acid $(4.75 \mathrm{~g}, 40.94 \mathrm{mmol})$ were added to the sample tumbler of the VAT Mk.10b and tumbled under a flow of dry $\mathrm{N}_{2}\left(\sim 45 \mathrm{~mL} \mathrm{~min}^{-1}\right)$. The flow of $\mathrm{N}_{2}$ was bubbled through the reservoir of $\mathrm{MeOH}$ and passed through the sample. After $4.5 \mathrm{~h}$, MeOH $(1 \mathrm{~mL})$ was added after $1 \mathrm{~h}, 2.5 \mathrm{~h}$ and $4.5 \mathrm{~h}$. An aliquot (0.10 g) was then removed and set aside. The remaining powders were tumbled in $\mathrm{N}_{2} / \mathrm{MeOH}$ for a further 2 days. The solvent reservoir was the removed and dry $\mathrm{N}_{2}$ passed through the tumbler for $2 \mathrm{~h}$. Recovered mass: $9.29 \mathrm{~g}$. A DSC of the final material showed one sharp endotherm at $176.85^{\circ} \mathrm{C}$.

\section{Salts}

\section{Carvedilol : Oxalic Acid (2:1) Salt}

Carvedilol freebase $(4.30 \mathrm{~g}, 10.58 \mathrm{mmol})$ and milled oxalic acid dihydrate $(0.68 \mathrm{~g}, 5.29 \mathrm{mmol})$ were added to the sample tumbler of the VAT Mk.10b and tumbled under a flow of dry $\mathrm{N}_{2}\left(420 \mathrm{~mL} \mathrm{~min}^{-1}\right)$. After $1 \mathrm{~h}$, a PXRD was taken of the free flowing powder showing no conversion to the reported Cav:OxA (2:1) salt (CCDC: YOKSUP). ${ }^{30}$ A flow of $\mathrm{N}_{2}$ bubbled through $\mathrm{MeOH}$ was added to the tumbler and tumbling resumed. Within $1 \mathrm{~h}$, peaks of the reported salt were seen along with broad peaks from an unknown form. After continuing the process overnight, $\mathrm{MeOH}(1 \mathrm{~mL})$ was added directly to the solids in the sample tumbler. After a total of $46 \mathrm{~h}$ in $\mathrm{N}_{2} / \mathrm{MeOH}$, only peaks from the salt were observed by PXRD. 
The powders were then removed from the sample tumbler. Recovered mass: $4.476 \mathrm{~g}$. A DSC was taken showing a small endotherm at $112.73{ }^{\circ} \mathrm{C}$ followed by the major, broad, endotherm onset at $195.39{ }^{\circ} \mathrm{C}$.

\section{Olanzapine : Nicotinic Acid (1:1) Salt}

Milled olanzapine free base $(1.00 \mathrm{~g}, 3.20 \mathrm{mmol})$ and nicotinic acid $(0.34 \mathrm{~g}, 3.20 \mathrm{mmol})$ were added to a $100 \mathrm{~mL}$ round bottomed flask along with a $1.5 \mathrm{~cm}$ stir bar. The rotovap trap was filled with $\mathrm{MeOH}$ and attached to the VAT Mk.1 apparatus. The system was placed under vacuum before being closed off and allowed to equilibrate with an atmosphere of $\mathrm{MeOH}$. Gentle rotation was started and left overnight ( $\sim 18 \mathrm{~h})$. The solids were then removed from the flask. Recovered mass: $1.27 \mathrm{~g}$. A DSC of the final material showed a single endotherm onset at $222.11^{\circ} \mathrm{C}$.

\section{Olanzapine : Oxalic Acid (1:1) Salt}

Milled olanzapine free base $(5.00 \mathrm{~g}, 16.00 \mathrm{mmol})$ and milled oxalic acid dihydrate $(2.02 \mathrm{~g}, 16.00 \mathrm{mmol})$ were added to the sample tumbler of the VAT Mk.10b and tumbled in atmospheric conditions. After $1 \mathrm{~h}$, a flow of $\mathrm{N}_{2}$ bubbled through $\mathrm{MeOH}$ was introduced into the sample tumbler $\left(\sim 20 \mathrm{~mL} \mathrm{~min}^{-1}\right)$. After $1 \mathrm{~h}$ of tumbling in $\mathrm{N}_{2} / \mathrm{MeOH}$ the solid had become bright orange. After $2.5 \mathrm{~h}$ of tumbling in $\mathrm{N}_{2} / \mathrm{MeOH}$ the tumbling was stopped, and the powders allowed to age for 3 days in a low flow of $\mathrm{N}_{2} / \mathrm{MeOH}\left(\sim 21 \mathrm{~mL} \mathrm{~min}^{-1}\right)$. Recovered mass: $6.33 \mathrm{~g}$. A DSC showed a broad endotherm with an onset at $230.86^{\circ} \mathrm{C}$ with a peak of $236.48^{\circ} \mathrm{C}$.

\section{Results and discussion}

\section{Sample Preparation and Experiments}

To help with a fast conversion, the individual components were ground separately to reduce their particle size* before the addition to the VAT apparatus. The mixing of the two powders was always done using the VAT apparatus itself as it would be done in a full-size RCD.

In the experiments reported here (see Table 1), $\mathrm{MeOH}$ was used due to its low cost, volatility and relatively low toxicity ${ }^{\diamond}$. Nevertheless, the final product of each experiment was tested for residual solvent by ${ }^{1} \mathrm{H}$ NMR. Incorporation of solvent into the co-crystal occurred at varying levels, (Table 1) and shows no obvious correlation to the structure of the coformers. It is entirely possible that a switch to other common solvents could result in lower levels of residual solvents, accelerate the formation of the desired solid form, or even produce a new one. However, since some solvent does get incorporated during VAT processes, the toxicity of the solvents used should always be carefully considered. At the same time, it is important to remember that the primary function of an RCD is for drying and removing residual solvents. This creates a highly efficient process where the final solid form can be created using a solvent vapour and then summarily dried without removal from the RCD - saving valuable processing time.

The Acl:Ura (1.1.5) cocrystal is usually crystallised from 10 volumes of EtOH per gram of Acl at a temperature of 55 ${ }^{\circ} \mathrm{C} .{ }^{31}$ With VAT, it was found that either $\mathrm{EtOH}, \mathrm{MeOH}$ or acetone could be used leading to a good conversion within 10 $\mathrm{h}$ without the need for elevated temperatures.

Both the Ari:Cat (1:1) (CCDC: KAJFIN ${ }^{32}$ ) and Ari:Res (1:1) (CCDC: KAJFEJ32) cocrystals were first reported as being crystallised by evaporation from $\mathrm{CHCl}_{3} / \mathrm{EtOH}(4: 1)$ at $70{ }^{\circ} \mathrm{C}$ before drying in a vacuum oven for 24 h. ${ }^{33}$ Subsequent attempts at cocrystallising via mechanochemistry by use of neat and liquid-assisted grinding in a mortar and pestle did 
Table 1. Table of experiments

\begin{tabular}{|c|c|c|c|c|c|c|c|}
\hline Expt & $\begin{array}{c}\text { Coformer } 1 \\
\text { (eq) }\end{array}$ & $\begin{array}{c}\text { Coformer } 2 \\
\text { (eq) }\end{array}$ & $\begin{array}{c}\text { Mass } \\
\text { Recovery } \\
\text { /g }\end{array}$ & $\begin{array}{c}\text { Mass } \\
\text { Recovery } \\
\%^{\S}\end{array}$ & $\begin{array}{l}\text { Time } \\
\text { / hr }\end{array}$ & $\begin{array}{c}\text { Residual } \\
\text { МeOH } \\
\text { /ppm }\end{array}$ & Ref \\
\hline 1 & Acalabrutinib (2) & Urea (3) & 5.42 & 91 & 24 & 600 & 30 \\
\hline 2 & Aripiprazole (1) & Catechol (1) & 5.79 & 93 & $3+18 h$ age & 3200 & 31 \\
\hline 3 & Aripiprazole (1) & Resorcinol (1) & 3.70 & 99 & 4 & 3400 & 31 \\
\hline 4 & Caffeine (1) & Citric Acid (1) & 9.45 & 95 & 42 & 1100 & 34 \\
\hline 5 & Carbamazepine (1) & Nicotinamide (1) & 7.28 & 93 & 28 & ND & 39 \\
\hline 6 & Isonicotinamide (1) & Resorcinol (1) & 7.70 & 96 & 18 & ND & 40 \\
\hline 7 & Nicotinamide (1) & Fumaric Acid (1) & 9.29 & 95 & 72 & ND & 41 \\
\hline 8 & Carvedilol (2) & Oxalic Acid (1) & 4.76 & 90 & 46 & ND & 28 \\
\hline 9 & Olanzapine (1) & Nicotinic Acid (1) & 6.80 & 96 & 18 & 500 & 43 \\
\hline 10 & Olanzapine (1) & Oxalic Acid (1) & 6.33 & 90 & $2.5+72 \mathrm{~h}$ age & 16000 & 44 \\
\hline
\end{tabular}

not produce either the Ari:Cat or Ari:Res cocrystals. Using the VAT process, both the Ari:Cat and Ari:Res cocrystals were successfully crystallised in $\mathrm{N}_{2} / \mathrm{MeOH}$ vapour at room temperature in approximately 4 hours. This both drastically increases the feasible scale of cocrystallisation compared to evaporation and decreases the energy input required for maintaining high temperature.

The Caf:CitA (1:1) cocrystal is a common and well-known cocrystal with several reported polymorphs obtained via mechanochemistry, with Form-I described as "disappearing". ${ }^{34-37}$ By tumbling the Caf and CitA in MeOH, it was found that Form-II (CCDC: KIGKER01) was formed after $\sim 18 \mathrm{~h}$.

Cbz:Nic (1:1) cocrystal has been previously reported to form spontaneously upon mixing, and that this can be accelerated in the presence of solvent vapours. ${ }^{12,38,39}$ Tumbling powders of Cbz and Nic in the VAT apparatus with $\mathrm{MeOH}$ vapour produced PXRD peaks of the reported cocrystal (CCDC: UNEZES) within $1 \mathrm{~h}$ of the experiment. ${ }^{40}$ After $20 \mathrm{~h}$ of tumbling in $\mathrm{MeOH}$ vapour, the peaks corresponding to both $\mathrm{Cbz}$ and Nic were hardly visible. After a slight excess of Nic was added, a complete conversion was seen by PXRD. A DSC of the final material showed very minor endotherms of $\mathrm{Cbz}$ and $\mathrm{Nic}$, with the major endotherm corresponding to the $\mathrm{Cbz}: \mathrm{Nic}(1: 1)$ cocrystal.

The Inic:Res (2:1) cocrystal was previously obtained from hot EtOH following evaporation over a few days (CCDC: VAKTUX). ${ }^{41}$ By tumbling Inic and Res in the VAT apparatus with an atmosphere of MeOH vapour, the cocrystal was formed in just $1 \mathrm{~h}$, and nearing completion after just $2 \mathrm{~h}$.

For Nic:Fum cocrystals, both the Nic:Fum (1:1) and Nic:Fum (2:1) have been reported (CCDC: NUKYAU01 and EDAPOQ respectively). ${ }^{42}$ The vapour-induced reaction of Nic and Fum was previously explored by using in-situ PXRD. It was found that in a 1:1 stoichiometric ratio of the two powders, that in the presence of either $\mathrm{MeOH}$ or $\mathrm{EtOH}$, the Nic:Fum (2:1) was made first, before a slow (over 6 h) conversion to the final Nic:Fum (1:1) cocrystal. When the same 1:1 ratio was investigated in VAT conditions, the peaks of 1:1 cocrystal were seen first. Upon addition of $\mathrm{MeOH}$ (1 mL) directly to the powders, the 2:1 cocrystal was seen after $1 \mathrm{~h}$, but had mostly disappeared after a further $4.5 \mathrm{~h}$.

Three previously reported salts were also made using the VAT technique. The Cav:OxA (2:1) salt (CCDC: YOKSUP) was previously made by mixing the components in $\mathrm{EtOH} / \mathrm{H}_{2} \mathrm{O}(1: 1, \mathrm{v} / \mathrm{v})$ at $70{ }^{\circ} \mathrm{C}$ for 20 min before being filtered and dried. ${ }^{30}$ Starting from a Cav freebase (CCDC: GIVJUQ0143), after $1 \mathrm{~h}$ of tumbling in $\mathrm{MeOH}$ vapour, the reported Cav:OxA (2:1) salt quickly formed concomitantly with the freebase along with very broad peaks of an unknown phase. After $22 \mathrm{~h}$ and the addition of $\mathrm{MeOH}(1 \mathrm{~mL})$ directly to the solids, the peaks of the unknown phase were no longer visible by PXRD. 
The Ola:NicA (1:1) salt (CCDC: TAQNUV) was originally produced by slow evaporation of aqueous $\mathrm{MeOH}$ (90\%). ${ }^{44}$ Using the VAT technique, the salt was produced in $\mathrm{MeOH}$ vapour within $18 \mathrm{~h}$.

An Ola:OxA (1:1) salt (CCDC: PEWPUF) was previously synthesised via liquid-assisted grinding (LAG) in a mortar and pestle with $\mathrm{MeCN}$ for $45 \mathrm{~min}$ and then heated at $80{ }^{\circ} \mathrm{C}$ for $15-20 \mathrm{~min} .{ }^{45}$ After tumbling in $\mathrm{MeOH}$ vapour for $18 \mathrm{~h}$ and aging for 3 days, the same Ola:OxA salt was produced without the need for elevated temperatures.

Overall, the VAT technique was successful in performing solid-solid conversions without any significant optimization - mainly for cocrystals. Several of the cocrystals underwent a full conversion (as evidenced by PXRD and DSC) in a matter of hours. Even for those systems exhibiting slow or modest conversion, it is reasonable to expect that the large number of variables such as temperature, solvent vapour, flow rate, rate of rotation/tumbling, time, and particle size facilitated by using an RCD could be screened to successfully obtain and optimise difficult solid-solid form conversions and ensure phase purity. It is important to note that by the very nature of the technique (i.e. solid to solid conversion), the phase purity of VAT is completely dependent on the correct stoichiometry of the solid form components being loaded into the RCD. In our examples, phase purity was determined by PXRD and DSC. It is possible that the limit of detection (LOD) provided by our instrumentation was not sufficient to detect the presence of other phases. Further determination of the LOD would be beneficial to quality control; however, a full LOD study for each sample was determined to be out of scope at the present time.

As the technique may make use of standard RCDs with little modification, we feel the uptake in industry could be quite rapid since it may provide benefits in terms of ease of production, yield, efficiency and environmental impact in terms of solvent usage and potential to be used at room temperature.

The VAT technique proved versatile across many different cocrystal systems. As previously stated by the Mehta group, "the catalytic effect of organic solvent vapours may be more widespread". ${ }^{13}$ This appears to be true, with the VAT technique proving successful in several transformations not reported here. It is conceivable that many more polymorphic transformations can occur with mechanical agitation while in environments of solvent vapour.

\section{Conclusions}

The VAT technique has been applied to produce several pharmaceutically active solid forms in quantitative yields with very low solvent usage. Since the use of RCDs are widespread in the pharmaceutical industry, the barrier to investment is lowered when adopting VAT processes. In addition, VAT can be further tested quite easily in an academic environment by using a standard rotary evaporator with a trap containing a volatile solvent, allowing for additional low-cost experimentation and modification before reaching industrial scales. The surprising number of positive experimental outcomes demonstrate the generality of this technique and that the use of vapour in solid form conversions may have widespread potential. Further to this, final solid form processing time could be massively lowered as the cocrystal can be both formed and dried inside the same RCD.

Given that the vapourised solvent is not actively consumed during the crystallisation, solvent waste is significantly diminished. RCDs are already designed to trap the solvents being removed from the drying solids. It is therefore feasible that the solvent used in the process would be both recoverable and recyclable in a closed-cycle system. ${ }^{25}$ Depending on impurity profile, the solvent could also be reused with minimal reprocessing. This could drastically lower the industrial use of solvents and provide a step forward towards greener crystallisation processes. ${ }^{46,47}$ 
The VAT technique can save both time and money and we hope that VAT will be considered an improved and readily scalable approach to the industrial production of cocrystals and salts of active pharmaceutical ingredients with good potential in other areas of industrial chemical processing.

\section{Conflicts of interest}

Several of the authors are co-inventors on filed patent application related to this work (WO2021/168561, PCT Application No. PCT/CA2021/050218, US Provisional Patent Application No. 62/981,817 and US Provisional Patent Application No. 63/093,481).

\section{Acknowledgements}

We thank Frank Barley and Robert Haw for their manufacturing expertise, suggestions, and input for the fabrication of the analogues for the rotary cone dryer. Edward McKenna is acknowledged for his scientific discussions and expert technical input on the day-to-day workings of in-use industrial scale rotary cone dryers. Dr. Martin Ehlert (Apotex, VP, Global API Technical) and Jason Fischer Apotex Pharmachem Inc., VP \& GM) are thanked for their review and support.

\section{Notes and references}

¥ Solid forms reported by patents vary in the extent to which they are characterised. We have elected to take the patents cited here at face value. If the patent reports the form as a cocrystal, it is described as such in this work. Some of these forms with further characterisation may reveal themselves to be salts or may fall on a salt-cocrystal continuum or otherwise. The full characterisation of reported forms of others was deemed to be outside the scope of this work.

* It may be found that particle size is of importance to the VAT technique. Work to understand and address this is ongoing.

- International Council for Harmonisation of Technical Requirements for Pharmaceuticals for Human Use (ICH) guidelines state that $\mathrm{MeOH}$ is a Class 2 solvent - permitted daily exposure (PDE) limit of $30.0 \mathrm{mg} \mathrm{day}^{-1}$ and a concentration limit of $3000 \mathrm{ppm} .{ }^{48}$

1 M. Karimi-Jafari, L. Padrela, G. M. Walker and D. M. Croker, Cryst. Growth Des., 2018, 18, 6370-6387.

2 M. Rodrigues, B. Baptista, J. A. Lopes and M. C. Sarraguça, Int. J. Pharm., 2018, 547, 404-420.

3 N. Blagden, S. J. Coles and D. J. Berry, CrystEngComm, 2014, 16, 5753-5761.

$4 \quad$ R. Sverdlov Arzi and A. Sosnik, Adv. Drug Deliv. Rev., 2018, 131, 79-100.

5 L. H. do Amaral, F. A. do Carmo, M. I. Amaro, V. P. de Sousa, L. C. R. P. da Silva, G. S. de Almeida, C. R. Rodrigues, A. M. Healy and L. M. Cabral, AAPS PharmSciTech, 2018, 19, 2687-2699.

6 Í. Duarte, R. Andrade, J. F. Pinto and M. Temtem, Int. J. Pharm., 2016, 506, 68-78.

7 P. McArdle and A. Erxleben, CrystEngComm, , DOI:10.1039/D1CE00715G.

8 K. I. Izutsu, T. Koide, N. Takata, Y. Ikeda, M. Ono, M. Inoue, T. Fukami and E. Yonemochi, Chem. Pharm. Bull., 2016, 64, 1421-1430.

9 R. B. Chavan, R. Thipparaboina, B. Yadav and N. R. Shastri, Drug Deliv. Transl. Res., 2018, 8, 1726-1739.

10 D. J. C. Constable, C. Jimenez-Gonzalez and R. K. Henderson, Org. Process Res. Dev., 2007, 11, $133-137$.

11 A. K. Salameh and L. S. Taylor, Pharm. Res., 2005, 22, 318-324.

12 A. Jayasankar, D. J. Good and N. Rodríguez-Hornedo, Mol. Pharm., 2007, 4, 360-372.

13 C. Ji, M. C. Hoffman and M. A. Mehta, Cryst. Growth Des., 2017, 17, 1456-1459.

14 S. L. James, C. J. Adams, C. Bolm, D. Braga, P. Collier, T. Friščić, F. Grepioni, K. D. M. Harris, G. Hyett, W. Jones, A. Krebs, J. Mack, L. Maini, A. G. Orpen, I. P. Parkin, W. C. Shearouse, J. W. Steed and D. C. Waddell, Chem. Soc. Rev., 2012, 41, 413-447.

15 I. Huskic, C. Lennox and T. Friščić, Green Chem., 2020, 4778523.

16 C. Mottillo, Y. Lu, M. H. Pham, M. J. Cliffe, T. O. Do and T. Friščić, Green Chem., 2013, 15, 2121-2131. 
S. H. Lapidus, A. Naik, A. Wixtrom, N. E. Massa, V. Ta Phuoc, L. del Campo, S. Lebègue, J. G. Ángyán, T. Abdel-Fattah and S. Pagola, Cryst. Growth Des., 2014, 14, 91-100.

K. Užarević, T. C. Wang, S.-Y. Moon, A. M. Fidelli, J. T. Hupp, O. K. Farha and T. Friščić, Chem. Commun., 2016, 52, 21332136.

M. J. Cliffe, C. Mottillo, R. S. Stein, D.-K. Bučar and T. Friščić, Chem. Sci., 2012, 3, 2495.

Y. Tanabe, Y. Maeno, K. Ohashi, H. Hisada, A. Roy, J. Carriere, R. Heyler and T. Fukami, Eur. J. Pharm. Biopharm., 2019, 136, 131-137.

D. Braga, S. L. Giaffreda, F. Grepioni, M. R. Chierotti, R. Gobetto, G. Palladino and M. Polito, CrystEngComm, 2007, 9, 879 .

D. Braga, S. L. Giaffreda, K. Rubini, F. Grepioni, M. R. Chierotti and R. Gobetto, CrystEngComm, 2007, 9, 39-45.

G. Kaupp, J. Chem. Eng. Process Technol., 2017, 08, 335.

Z. Pakowski and A. Mujumdar, in Handbook of Industrial Drying, Fourth Edition, CRC Press, 2014, pp. 681-701. US7745624B2, 2006, 1-7. US8471011B2, 2013, 1-6.

C. F. Macrae, I. Sovago, S. J. Cottrell, P. T. A. Galek, P. McCabe, E. Pidcock, M. Platings, G. P. Shields, J. S. Stevens, M. Towler and P. A. Wood, J. Appl. Crystallogr., 2020, 53, 226-235.

A. Rohatgi, 2020, v4.4, https://automeris.io/WebPlotDigitizer.

L. F. Diniz, P. S. Carvalho, W. da Nova Mussel, M. I. Yoshida, R. Diniz and C. Fernandes, Cryst. Growth Des., 2019, 19, 4498-4509. WO 2019/041026 A1, 2018, 1-40.

J. B. Nanubolu and K. Ravikumar, CrystEngComm, 2016, 18, 1024-1038.

M. Y. Cho, P. Kim, G. Y. Kim, J. Y. Lee, K. H. Song, M. J. Lee, W. Yoon, H. Yun and G. J. Choi, Cryst. Growth Des., 2017, 17, 6641-6652.

S. Karki, T. Friščić, W. Jones and W. D. S. Motherwell, Mol. Pharm., 2007, 4, 347-354.

J. P. Smit and E. J. Hagen, J. Chem. Crystallogr., 2015, 45, 128-133.

A. Mukherjee, R. D. Rogers and A. S. Myerson, CrystEngComm, 2018, 20, 3817-3821.

D. Hasa, M. Marosa, D. K. Bučar, M. K. Corpinot, D. Amin, B. Patel and W. Jones, Cryst. Growth Des., 2020, 20, 11191129.

A. A. L. Michalchuk, K. S. Hope, S. R. Kennedy, M. V. Blanco, E. V. Boldyreva and C. R. Pulham, Chem. Commun., 2018, 54, 4033-4036.

K. K. Arora, N. G. Tayade and R. Suryanarayanan, Mol. Pharm., 2011, 8, 982-989.

S. G. Fleischman, S. S. Kuduva, J. A. McMahon, B. Moulton, R. D. Bailey Walsh, N. Rodríguez-Hornedo and M. J.

Zaworotko, Cryst. Growth Des., 2003, 3, 909-919.

P. Vishweshwar, A. Nangia and V. M. Lynch, CrystEngComm, 2003, 5, 164-168.

L. Orola and M. V. Veidis, CrystEngComm, 2009, 11, 415.

H. S. Yathirajan, S. Bindya, T. V. Sreevidya, B. Narayana and M. Bolte, Acta Crystallogr. Sect. E Struct. Reports Online, 2007, 63, o542-0544.

K. Ravikumar, G. Y. S. K. Swamy, B. Sridhar and S. Roopa, Acta Crystallogr. Sect. E Struct. Reports Online, 2005, 61, 02720-02723.

K. K. Sarmah, P. Sarma, D. R. Rao, P. Gupta, N. K. Nath, M. Arhangelskis and R. Thakuria, Cryst. Growth Des., 2018, 18, 2138-2150.

R. A. Sheldon, ACS Sustain. Chem. Eng., 2018, 6, 32-48.

C. Jiménez-González, D. J. C. Constable and C. S. Ponder, Chem. Soc. Rev., 2012, 41, 1485-1498.

ICH, Impurities: Guideline for Residual Solvents Q3C(R6), 2016. 